\section{ASSESMENT OF PATIENT SATISACTION FOR CERVICAL SCAR POST THYROIDECTOIMY}

KEY WORDS: Thyroidectomy, Midcervical Scar, Scar Consciousness, Satisfaction With Appearance.

\section{Dr. Devendra}

Pankaj*

\section{Dr. Neha Singh}

Assistant professor Department of ENT-HNS American international institute of Medical Sciences Udaipur, Rajasthan. *Corresponding Author

ENT Clinic, Muzaffarpur, Bihar

Background:- Thyroidectomy is a common procedure performed for thyroid disease these days. Plan of surgery depends on histology, location and size of lesion. Thyroidectomy is preceded by conventional midcervical skin crease incision, performed by Theoder kocher in late 1870, to advanced mininmal invasive technique. Minimal invasive techniques have certain upright from conventional surgery. This study aims to study patient satisfaction for cervical scar with thyroidectomy conventional kocher's incision. Material \& Method:-Sixty five 65 patient underwent thyroidectomy from September 2017 to February 2020 at American international institute of medical sciences Udaipur, Rajasthan. Patient clinical data retrospectively reviewed and patient scar satisfaction acquired telephonically by using validated patient scar assessment questionnaire and data analyzed statistically. Result:- Around 95\% patients show high level of satisfaction in the study having scores consistent with scar satisfaction after conventional thyroidectomy. Majority of patients were satisfied with the appearance of their scars, around $5 \%$ of patients $(n=3)$ reported significant levels of self consciousness. Conclusion:- . Majority of patients were satisfied with their scars post thyroidectomy. Despite high level of satisfaction there are people shows significant levels of consciousness. There is need of further study to decide certain factor whether encouraging minimal invasive technique over conventional thyroid surgery.

\section{BACKGROUND:}

Thyroidectomy is most common surgery performed at many surgical institutes, using conventional Kocher's incision for surgery. Conventional kocher's incion developed by theoder kocher in late 1870(1). Kocher used mid cervical incision, two finger breadth above sternal notch as skin crease incision as it gives favorable outcome cosmetically.

Since with advancement of techniques minimal invasive surgical techniques are coming in vision of surgery(2), thyroid surgeries are also not away from becoming part of this minimal invasive surgical technique as giving excellent results less post operative pain, better scar result, reduced hospital stay, overall less off from working place giving monitory benefit(3-5).

With all the benefits surgical techniques are fuelled towards minimally invasive techniques. With advancement of techniques in all fields, these are not readily available in small surgical setup, despite of certain benefits over conventional surgery. They still preferring conventional kocher's incision $(6-8)$.

The aim of study is to assess satisfaction of patient regarding midcervical surgical scar.

\section{Materials \& methods:-}

This study was conducted 65 age and sex matched cases of thyroid disease, underwent thyroidectomy surgery in department of ENT-HNS, American Institute of Medical Sciences, Udaipur, Rajasthan between February 2017 to September 2020.

All the history and details recalled retrospectively from institute's records. The entire verbal and informed consent took before given the questionnaire data of validated patient scar assessment questionnaire.

All the cases of revision surgery, neck dissection, absent o negative drain, post surgery RT/Iodine therapy were excluded from surgery.

All patient given consent for study administered patient scar assessment qustionnaire telephonically in view of covid pandemic. And response were recorded and analysed |www.worldwidejournals.com statistically.

We have used patient scar assessment questionnaire to collect response regarding satisfaction post surgical mid cervical scar, which is a validated scar assessment tool.(9) Which consist of five subscale symptoms, appearance, scar consciousness, satisfaction with symptoms, and satisfaction with appearance(5). Each of these subscales is independent of each other designed in Patient Scar Assesment Questionnaire, so we can use them separately. Symptom subscale is the only subscale which is not validated properly and need further evaluation.

Here we used three of five subscales scar consciousness, satisfaction with symptoms, and satisfaction with appearance.

The scar consciousness subscale consist o 6 questionnaire, satisfaction with symptoms subscale consist of 5 questionnaires, and satisfaction with appearance consist of 8 questionnaires. Response of each questionnaire recorded on likert type of scale, which ranges from one to four. One is recorded as minimum response as very satisfied and our as maximum response as very dissatisfied. So response for scar consciousness subscale ranges from 6 to 24 , for satisfaction with symptoms subscale 5 to 20, and for satisfaction with appearance 8 to 32 . And total response for patient scar assessment questionnaire ranged minimum 19 to 76 maximum. The higher response therefore represents the decreased satisfaction result of scar cosmetically.

All the data analyzed statistically using one way analysis of variance (ANOVA) and independent $t$ test for mean.

\section{Results:-}

Total 65 patients enrolled in the study out of which 60 females and 5 were male patients. Youngest participant was 16 year old and oldest one was 62 year old. Total $57(87.69 \%)$ patients underwent for hemithyroidectomy, 3 (4.6\%) patients for subtotal thyroidectomy and $5(7.6 \%)$ patients underwent for total thyroidectomy. 2 (3\%) patients were operated or malignancy and 63(97\%) pateints operated for benign lesions.

\section{Male female ratio:-}

$\mathrm{M}: \mathrm{F}=\mathrm{l}: 12$ 


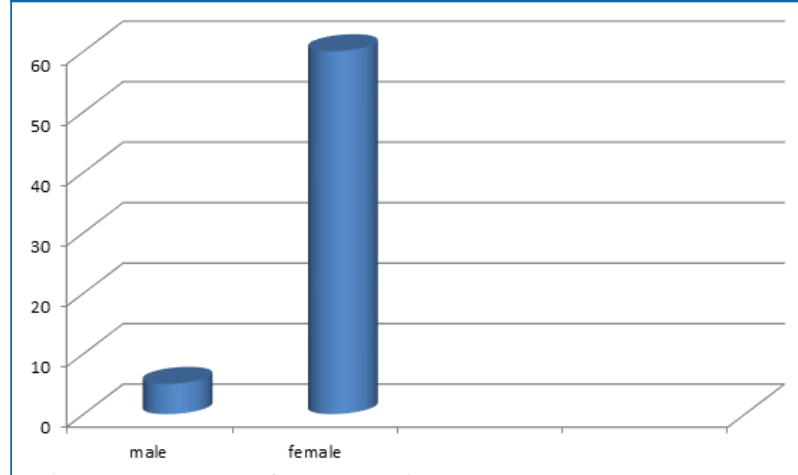

Diagram 1:- Male female ratio

Histopathological distribution:-

Table 1:- Distribution according histopathology

\begin{tabular}{|l|l|}
\hline Benign & Malignant \\
\hline 2 & 63 \\
\hline
\end{tabular}

Distribution according surgery performed:-

Table 2:- Distribution according surgery performed

\begin{tabular}{|l|l|l|}
\hline Hemithyroidectomy & $\begin{array}{l}\text { Subtotal } \\
\text { thyroidectomy }\end{array}$ & $\begin{array}{l}\text { Total } \\
\text { thyroidectomy }\end{array}$ \\
\hline 57 & 3 & 5 \\
\hline
\end{tabular}

\section{Results of PSAQ:-}

Around 95\% patients show high level of satisfaction in the study having scores consistent with scar satisfaction after conventional thyroidectomy.

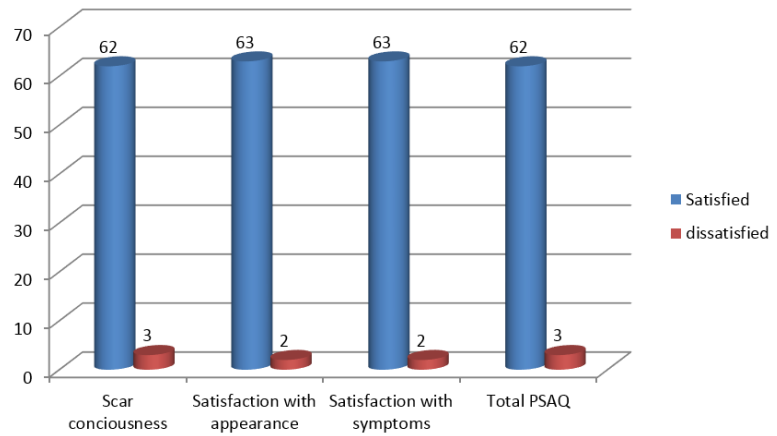

Diagram 2:- Distribution of subscale satisafction scores with various parameters, (x axis shows number ofpersons, y axis shows subscale categories)

The mean score for scar consciousness subscale was $7.76 \pm 1.88$ and for satisfaction with symptoms subscale $6.13 \pm 1.45$ and for satisfaction with appearance $10 \pm 2.35$. The mean total PSAQ score was $23.90 \pm 5.35$, out of a total maximum score of 76, and scores ranged from 19 to 41 . A score of 38 or greater was considered indicative of patient dissatisfaction with scar outcome. There are 3 patients above value of 38 , shows dissatisfaction for outcome of thyroidectomy surgical scar. 3 patients showed highly consciousness for surgical scar.

There is no variations in outcome of surgical scar depends on gender, histopathology and type of surgery performed.

\section{DISCUSSION:-}

Conventional thyroidectomy is the procedure for thyroid ailments, commonly performed by kocher's incision at many surgical setup (1). Conventional thyroid incision proposed by kocher leads prolonged hospital stay, post operative pain and concern for post operative surgical scar. This has begun a drive towards newer and advanced modalities like minimal invasive surgery, robotic surgery, trans-axillary, transoral approach (10). These advanced techniques are not also readily available at small surgical setup (17) where conventional thyroidectomy can easily perform.
This study shows satisfaction of patients post conventional mid cervical incision thyroidectomy by kocher. The findings of this study correlate with others which found that overall patient scar satisfaction after conventional thyroidectomy incision is very high $(11-13,24)$.

In this study 3 patients were above value of 38 , shows dissatisfaction for outcome of thyroidectomy surgical scar and 3 patients showed consciousness for surgical scar.

This study showed that there is no variations in outcome of surgical scar depends on gender, histopathology and type of surgery performed which was in discordance with studies that demonstrated difference in scar satisfaction based on patient gender, with female patients generally having a greater degree of dissatisfaction compared to males $(11,14)$

In this study we used for closure of wounds continuous subcuticular prolene suture for skin closure. Data in Literature shows that the method of closure chosen with regards to absorbable and non-absorbable sutures dose not significantly impact patient outcome of the scar $(15,16)$. Some factors that have been shown to improve scar outcomes are marking of patients in the upright position, avoiding elevation of subplatysmal flap to decrease postoperative neck edema and healing times, and avoidance of drain usage where possible (2). Minimally invasive surgery in thyroidectomy is move around the absence of a cervical incision along with other benefits of post-surgical recovery time and improved pain.

These procedures are generally more expensive, than conventional surgical method and are not always available in small health care systems (17).

The role of cervical incision is clearly not mentioned literature $(3,7,12,18-21)$. Patients are more concerned is more about post operative complications like voice change, complete removal o disease (14). These above factors were beyond the scope of this study there may also be a consideration of level of education, marriage status, parity and socioeconomic factors that may play a role in patient satisfaction and perceived scar outcomes (13). The data collected was also self-reported over telephone by patients and did not have an objective component such as scar length or observer assessment as would be considered in other scar assessment tools $(22,23)$.

\section{CONCLUSION:-}

Majority of patients (95\%) show high level of satisfaction post thyroidectmy with conventional midcervical incision despite significant level of scar consciousness in some patients. The role of minimal invasive surgery directly related to post operative stay in hospital indirectly to finance as less off from work place and less discomfort. There is need of further study to decide certain factor whether encouraging minimal invasive technique over conventional thyroid surgery.

\section{REFERENCES:-}

1. Linos D, Chung WY, editors. Minimally invasive thyroidectomy. Berlin: Springer, 2012:257.

2. Terris DJ, Seybt MW, Elchoufi M, et al. Cosmetic Thyroid Surgery: Defining the Essential Principles. Laryngoscope 2007;117:1168-72. 10.1097/MLG. $0 \mathrm{~b} 013 \mathrm{e} 318053 \mathrm{db} 8 \mathrm{f}$

3. Miccoli P, Berti P, Raffaelli M, et al. Comparison between minimally invasive video-assisted thyroidectomy and conventional thyroidectomy: $A$ prospective randomized study. Surgery 2001;130:1039-43. 10.1067/msy. 2001.118264

4. Zachariah SK. Gas-less Video-assisted Thyroidectomy for a Solitary Thyroid Nodule: Technical Report of the First Case Performed at a Rural Teaching Hospital in India and Review of Literature.J Surg Tech Case Rep 2012;4:27-31. $10.4103 / 2006-8808.100350$

5. Linos D. Minimally invasive thyroidectomy: A comprehensive appraisal of existing techniques. Surgery 201 1;150:17-24.10.1016/j.surg.2011.02.018

6. Anuwong A, Ketwong K, Jitpratoom P, et al. Safety and Outcomes of the Transoral Endoscopic Thyroidectomy Vestibular Approach. JAMA Surg 2018;153:21-7.10.1001/jamasurg.2017.3366

7. Russell JO, Razavi CR, Garstka ME, et al. Remote-Access Thyroidectomy: A Multi-Institutional North American Experience with Transaxillary, Robotic 
Facelift, and Transoral Endoscopic Vestibular Approaches. J Am Coll Surg 2019;228:516-22.10.1016/j.jamcollsurg.2018.12.005

8. Russell JO, Razavi CR, Shaear M, et al. Transoral Vestibular Thyroidectomy: Current State of Affairs and Considerations for the Future. J Clin Endocrinol Metab 2019. [Epub ahead of print]. 10.1210/jc.2019-00116

9. Durani P, McGrouther DA, Ferguson MW. The Patient Scar Assessment Questionnaire: A Reliable and Valid Patient-Reported Outcomes Measure for Linear Scars. Plast Reconstr Surg 2009;123:1481-9. 10.1097/PRS. Ob013e318la205de

10. Juarez MC, Ishii L, Nellis JC, et al. Objectively measuring social attention of thyroid neck scars and transoral surgery using eye tracking. Laryngoscope 2019. [Epub ahead of print]. 10.1002/lary.27933

11. Best AR, Shipchandler TZ, Cordes SR. Midcervical scar satisfaction in thyroidectomy patients. Laryngoscope 2017;127:1247-52. 10.1002/lary. 26177

12. Linos DA, Petralias A. Commentary on: A prospective comparison of patient body image after robotic thyroidectomy and conventional open thyroidectomy in patients with papillary thyroid carcinoma. Surgery 2014;156:126-7.10.1016/j.surg.2014.03.043

13. Linos D, Economopoulos KP, Kiriakopoulos A, et al. Scar perceptions after thyroid and parathyroid surgery: Comparison of minimal and conventional approaches.Surgery 2013;153:400-7.10.1016/j.surg.2012.08.008

14. Abdul-Sater L, Henry M, Majdan A, et al. What are thyroidectomy patients really concerned about? Otolaryngol Head Neck Surg 2011;144:685-90. $10.1177 / 0194599811399556$

15. Kundra RK, Newman S, Saithna A, et al. Absorbable or non-absorbable sutures? A prospective, randomised evaluation of aesthetic outcomes in patients undergoing elective day-case hand and wrist surgery. Ann R Coll Surg Engl 2010;92:665-7.10.1308/003588410X12699663905113

16. Holger JS, Wandersee SC, Hale DB. Cosmetic outcomes of facial lacerations repaired with tissueadhesive, absorbable, and nonabsorbable sutures. Am J Emerg Med 2004;22:254-7. 10.1016/j.ajem.2004.02.009

17. Billmann F, Bokor-Billmann T, Voigt $J$, et al. Effects of a cost-effective surgical workflow on cosmesis and patient's satisfaction in open thyroid surgery. Int $J$ Surg 2013;11:31-6.10.1016/j.ijsu.2012.11.004

18. Perigli G, Cortesini C, Qirici E, et al. Clinical Benefits of Minimally Invasive Techniques in Thyroid Surgery. World J Surg 2008;32:45-50. 10.1007/s00268007-9259-0

19. Bokor T, Kiffner E, Kotrikova B, et al. Cosmesis and body image after minimally invasive or open thyroid surgery. World J Surg 2012;36:1279-85. 10.1007/s00268-012-1563-7

20. O'Connell DA, Diamond C, Seikaly H, et al. Objective and subjective scar aesthetics in minimal access vs conventional access parathyroidectomy and thyroidectomy surgical procedures: a paired cohort study. Arch Otolaryngol Head Neck Surg 2008;134:85-93. 10.1001/archotol.134.1.85

21. Toll EC, Loizou P, Davis CR, et al. Scars and satisfaction: do smaller scars improve patientreported outcome? Eur Arch Otorhinolaryngol 2012;269:309-13.10.1007/s00405-01 1-1613-z

22. Mundy LR, Miller HC, Klassen AF, et al. Patient-Reported Outcome Instruments for Surgical and Traumatic Scars: A Systematic Review of their Development, Content, and Psychometric Validation. Aesthetic Plast Surg 2016;40:792-800.10.1007/s00266-016-0642-9

23. Durani P, McGrouther DA, Ferguson MW. Current scales for assessing human scarring: A review. J Plast Reconstr Aesthet Surg 2009;62:713-20. 10.1016/j.bjps.2009.01.080

24. Felix, C., Russell, J. O., Juman, S., \& Medford, S. (2019). Cervical scar satisfaction post conventional thyroidectomy. Gland surgery, 8(6), 723-728. https://doi.org/10.21037/gs.2019.11.17 